\title{
Trabajo, no trabajo y neo/postfordismo
}

\author{
Francisco Quintana
}

Universidade de Barcelona

\begin{abstract}
Los cambios socioeconómicos y tecnológicos (implantación de sistemas robóticos, re-engineering, lean management, lean production, etc.) ocurridos en las formaciones capitalistas en las últimas tres décadas han tenido profundas repercusiones en el ámbito de la organización productiva y de las técnicas de fabricación. En este contexto, catalogado como neo/postfordista, el trabajo productivo(/reproductivo), que tiene en la ciencia aplicada y en las formas de vida (socialidad) los principales ingredientes, muta a través de esa compleja articulación de sistemas máquina y régimen flexible. Uno de los efectos de estas transformaciones ha sido la dualización social: estables y precarios o excluidos (contingent jobs, working poor, parados estructurales, etc.). Ante ello, surgen diversas propuestas: desde aquellos que sostienen (Castells, etc.) que los nuevos sectores económicos compensaran el paro tecnológico inducido hasta los que afirman (Offe, "dinero gratis", etc.) que el carácter paradójico e irreversible de estos procesos legitima el derecho a una renta garantizada y sin contrapartidas para los excluidos. Con todo, lo que pone de manifiesto este escenario es la necesidad de elaborar una teoría social (y política) crítica acorde con los procesos postindustriales (capital cognitivo, producción inmaterial, etc.) que contemple, entre otras, las aportaciones ludditas o las de la antropología de Clastres.
\end{abstract}

Palavras-chave: Neofordista, Postfordista, Sociedad fábrica, Metrópoli, General intellect, Reflexividad, Disociación psíquica.

\section{Work, no-work and neo/postfordism}

The socioeconomic and technological changes (such as robotics, reengineering, lean management, lean production,...) that happened in the capitalist formations over the last three decades have had deep impact in the production line organization and in the mass production techniques. Within this context, described as "neopostfordism", the productive/ reproductive work that has its main ingredients in applied science and in the ways of life transforms itself through this complex articulation of machine systems and flexible hiring. One of the results of these changes has been a social duality such as stable and unstable contracts or left outs (contingent jobs, working poor, structural unemployed). There are different answers to this process. From the ones who hold up that the new economic groups will make up for the unemployment brought in (Castells, etc.) to the ones who reaffirm that the irreversible paradoxical aspect of this process recognizes the right to a fix rent for the left outs (Offe, "free money", etc.). All in all, what is a must in front of this performance is to build up a critic social (and political) theory according to the postindustrial procedures (cognitive capital, immaterial production...)A new theory to deal with "ludditas" contributions or with the Clastres anthropology ones.

Keywords: Neofordism, Postfordism, Factory society, Metropolis, General intellect, Reflexivity, Psychic dissociation.

\section{Escenario neo/postfordista}

L as transformaciones acontecidas en el capitalismo contemporáneo en las últimas tres décadas ponen de manifiesto, particularmente en las regiones industrializadas, la existencia de profundas transformaciones en la organización económica, tecnológica y en las relaciones sociolaborales. Los tiempos de la "sociedad fábrica" ${ }^{1}$ y del "pacto fordista", con trabajo estable y bien remunerado, basados en el compromiso de armisticio entre capital y trabajo y que contaba, en éste caso, con el respaldado de la fuerza estructural obrera, han pasado a la historia. Según las previsiones de la Comisión Europea para el 2004 el desempleo en algunos de los principales países de la Unión Europea iba a ser el siguiente: Alemania $9,1 \%$, Francia 9,6\%, Italia 8,6\% y Bélgica $8,3 \%$. Estas cifras suponían, por ejemplo, para un país como Alemania, la cantidad de de 4,3 millones de parados. Y para España, haber pasado

1 Quintana et al. (2002). Con una enfoque más general, que incluye un análisis de los cambios económicos, culturales y de la configuración urbana en relación con el salto hacia el postindustrialismo, ver: Harvey (1998) y Soja (2003). 
de 133.000 parados en 1970, antes de la reestructuración, a una cifra de 2.1164 .100 parados y una tasa de desempleo del 11,3\%, como se desprende de la Encuesta de Población Activa (EPA) del 2004. Esta problemática, estrechamente ligada a la flexibilización socioeconómica y a la implantación de sistemas de fabricación y organizativos basados en las Tecnologías de la Información y la Comunicación (TIC), permite hablar de precariedad sociolaboral y de paro estructural, lo que conlleva, en un marco de políticas sociales en el que o no hay "welfare" o allí donde había está siendo recortado, un aumento considerable de la pobreza.

Así pues, pese a lo afirmado por los teóricos neoconservadores de la "sociedad del ocio" o del "postindustrialismo", o bien, desde el pensamiento crítico, por autores como Rifkin (1997), la situación en la que nos encontramos no es exactamente la del "fin del trabajo", aunque lo que probablemente si es cierto es que una parte de la sociedad no trabajará nunca o casi nunca. Se trata de procesos complejos en los que intervienen distintos factores: sustitución de la fuerza de trabajo humana por máquinas (sistemas computerizados, telemáticos, autómatas industriales, etc.) que comporta una drástica reducción de la demanda de trabajadores; aumento de la valorización y del cómputo de la riqueza producidos mediante diversos procedimientos (crecimiento exponencial de la productividad, disminución del tiempo de trabajo socialmente necesario, prolongación de la jornada de trabajo, incremento de las horas extras o "fuera de normas", etc.); flexibilización del régimen regulador de las relaciones laborales.

Las modificaciones en el estatuto del trabajo, que afectan a la relación entre espacio/tiempo de trabajo y de no-trabajo, suponen, también, que el trabajo ha dejado de tener ese carácter central que tuvo cuando fábrica y sociedad no coincidían exactamente, con los sistemas fordistas (producción en cadena o flujo continuo, standarización de las mercancías, etc.) y taylorista (separación entre diseño y ejecución, fraccionamiento de los tiempos y movimientos, etc.). Entonces significaba: para el capital, fuente de valorización; para el obrero de la cadena, obrero masa, en tanto que subjetividad conflictiva y antagonista expresada de distintas maneras (absentismo, sabotaje, huelga salvaje, etc.), punto de arranque de las reivindicaciones y del contrapoder. En el actual periodo, sin embargo, las cosas son distintas. En este sentido, desde la óptica de la organización socioeconómica y tecnológica, distinguiremos a grandes rasgos dos grandes modelos de referencia que se que se engarzan en zonas y segmentos de la producción (y reproducción) de manera no siempre sistemática, a saber:

a) Neofordismo; fordismo y fordismo disperso, precario, que recurre al trabajo repetitivo, en serie, de las economías de escala; con baja intensidad tecnológica; sin las garantías de estabilidad y remuneración del "pacto fordista";

b)Postfordismo; combinado de TIC y saber social incorporado a la producción (y reproducción) del circuito de la mercancía; media o alta intensidad tecnológica (técnicas de fabricación y organizativas); flexibilidad sociolaboral.

Por otra parte, sucede algo inusual al recuperarse o crecer la economía sin que al propio tiempo haya creación de empleo - "jobless recovery" - lo que constituye una refutación de las concepciones de la ortodoxia económica. Si examinamos las cosas con más detalle comprobaremos, según Rodriguez (1998, pp. 90-92), que el desempleo tiene que ver, aparte de otros factores, con el "estancamiento" o la "inversión"de la tendencia general a la reducción de la duración anual de la jornada laboral a tiempo completo ocurrida desde mediados de los ochenta. En los países industrializados, el tiempo de trabajo remunerado, a tiempo completo y fijo ha disminuido mientras crecía el empleo a tiempo parcial y temporal y la prolongación de las jornadas. Un informe del CES de 1996 indicaba que más del 50\% de los empleos creados en la Unión Europea desde 1980 fueron temporales o "atípicos". Esto incidiría en el hecho de que en la OCDE el ritmo de creación del empleo no haya variado en 
los último 35 años y que tampoco haya disminuido ni la cantidad de trabajo ni el ritmo de crecimiento económico.

No obstante, hay que tener en cuenta que para la estabilidad económica tan significativo es el paro estructural inducido por la innovación tecnológica como la degradación de las condiciones sociolaborales. No hay que olvidar, como sostiene Offe (1994, p. 69), que hay dos salarios de equilibrio y no uno: salario de equilibrio que "despeja el marcado de trabajo", y salario de equilibrio que "despeja el mercado de bienes"; ambos son distintos pero se implican mutuamente: si no se despeja el mercado de trabajo (evita el desempleo) no se despeja el de bienes, y viceversa. Por otra parte, en cuanto a los aspectos de regulación institucional, afirma:

El "problema del desempleo" se evidencia como la manifestación más obvia del fracaso de este modelo institucional clave que es el trabajo contractual. Pero el desempleo tasado es un indicador engañoso y demasiado eufemístico, ya que subestima sistemáticamente la envergadura de este fracaso institucional.

El "desempleo" es, a lo sumo, una medida incompleta si pretendemos evaluar la verdadera extensión del fracaso del modelo institucional del contrato laboral y del mercado de trabajo. Este fracaso institucional adopta muchas formas, algunas visibles, otras no tan obvias. Para captar como conceptos toda la gama de fenómenos relevantes, uno está tentado de recurrir a difíciles neologismos conceptuales como "precariedad de la situación social" y "precariedad de la subsistencia", evocando el término "precariedad" la connotación de inestabilidad e imprevisibilidad nociva, así como la falta de reconocimiento y aprecio social que va unido a esa condición. Dicho en pocas palabras, el contrato laboral falla tanto en asignar un "sitio" en la sociedad a un creciente número de personas como en proporcionarles ingresos y protección adecuados (Offe, 1997, pp. 12-13).

En suma, lo que pone de relieve esta doble precariedad es el derrumbe o liquidación de lo que han sido los pilares del orden social de la "sociedad fábrica" o "sociedad del trabajo", a saber: "contrato laboral" y "paradigma del pleno empleo". Y todo además cuando se produce, con altibajos (manifestaciones agudas de la crisis estructural, ralentización...), una gran aumento de la riqueza medible en términos de Producto Social Bruto (PSB) o de la acumulación bruta de capital por varias razones, esto es: desde principios del siglo XX el tiempo de trabajo se ha reducido a la mitad y la producción medida en PSB o en PIB se ha multiplicado por 15; por otro lado, en la actualidad un trabajador produce 4 veces más que hace 35 años (Bermejo, 1997, p. 222).

\section{Lecturas de esta mutación}

Por lo que se refiere al análisis de estos cambios, uno de cuyos ejes ha sido la metamorfosis del trabajo, verificamos la existencia de diversas y contrapuestas lecturas, que van desde quienes sostienen que el cambio tecnológico y sus repercusiones en la productividad y en la apertura de nuevos sectores en la economía contribuirán a equilibrar la balanza del desempleo tecnológico, hasta aquellos que profetizan la "sociedad del ocio".

Así, Castells (1998) distingue, en lo concerniente al cambio tecnológico y sus efectos en el mercado laboral, entre, por una parte, EEUU y Japón, y, por otra, Europa, al afirmar que en EEUU, si bien los puestos de trabajo tradicionales en la industria han corrido la misma

2 En relación con el paso de la "sociedad fábrica" al "territorio", en los 70 y 80, para configurar lo que denominamos, como un eco de Foucault y Deleuze, "sociedad metrópoli" o "sociedad del control y la comunicación”, producto de la diseminación por el territorio de las estructuras productivas y reproductivas mercantilizantes, ver Quintana y Pin (1980). 
suerte que los de la agricultura, esta pérdida ha quedado compensada por los puestos creados en la industria de alta tecnología y en los servicios. EEUU y Japón, prototipo de economías industriales avanzadas, serían, en este sentido, según el "Employment Outlook" de la OCDE, los países que habrían creado más puestos de trabajo en las dos últimas décadas. Un componente inédito de la nueva situación radica en la incorporación "masiva" de la mujer al campo laboral. En líneas generales, por tanto, aunque la cifra de puestos de trabajo en fabricación en la OCDE disminuye, en cambio en los países periféricos aumenta. Esto permite afirmar a Castells que la cuestión del desempleo es principalmente un problema europeo causado por unas "políticas macroeconómicas desacertadas" y por un funcionamiento de las instituciones que desalienta la inversión privada. Empíricamente, añade, se constata que a grados desarrollo tecnológico más elevado corresponden tasas de desempleo más bajas (1998, p. 284).

La postura de Castells entra en abierta contradicción con la de autores que, como King (1991), Rifkin (1997), Aznar (1994), Aronowitz y Di Fazio (1994), que anuncian un futuro con sociedades con menos trabajo o sin él. Sobre este particular, Castells (1998) sostiene:
(...) como tendencia general, parece que no existe una relación estructural sistemática entre la difusión de las tecnologías de la información y la evolución de los niveles de empleo en el conjunto de la economía. Hay puestos de trabajo que se desplazan mientras que se crean otros nuevos, pero la relación cuantitativa entre las pérdidas y las ganancias varía de unas empresas, industrias, sectores, regiones y países a otros, dependiendo de la competitividad, las estrategias comerciales, las políticas gubernamentales, los entornos institucionales y la posición relativa en la economía global. El resultado específico de la interacción de la tecnología de la información y el empleo depende en buena medida de factores macroeconómicos, estrategias económicas y contextos sociopolíticos. En general, las proyecciones de empleo para los países de la OCDE a comienzos del siglo XXI prevén un aumento significativo de los puestos de trabajo para los Estados Unidos y un crecimiento moderado para Japón y la Comunidad Europea (12 países): para el periodo 1992-2005, el incremento neto de puestos de trabajo proyectado sería 24 millones (un aumento total del 19\% durante el periodo) en los Estados Unidos ; para Japón, de 4 millones (un aumento del 6\%); y para la Unión Europea en torno a 10 millones (un aumento aproximado de un 6\% o 7\%) (pp. 292-293).

Sin embargo, hay que puntualizar que Castells hace depender estas previsiones de la evolución y del valor que adoptan ciertos elementos: decisiones adoptadas en cuanto al uso de la tecnología, política migratoria, regulación de la jornada laboral, sistema de relaciones industriales, etc. que en muchos casos son sumamente aleatorios.

Con todo, a esta interpretación se le se pueden plantear serias objeciones. De inmediato, que el voluminoso arsenal de datos aportado por Castells resulta sesgado, ya que extrapola a otras regiones lo que en principio es privativo de un subgrupo de países (EEUU, Japón) y de un periodo, pero aún así sería muy discutible; no deja de ser significativo, por ejemplo, que países que como Japón para los que el desempleo era algo desconocido, actualmente, con la desregulación y el consiguiente derrumbe de las fidelidades milenarias, registre porcentajes de paro entre el 4\% y el 5\%. Por otra parte estarían los aproximadamente 1000 millones de parados en el mundo que contabiliza la Organización Internacional del Trabajo (OIT). Habría que destacar, también, ligado a la reducción de la demanda de fuerza de trabajo, la degradación de las condiciones sociolaborales con un goteo constante de "working poor", trabajadores cuyo salario es inferior al umbral de la pobreza. Finalmente estaría la reducción en costes y en tiempo de trabajo que algunos usos de las nueves tecnologías comportan.

Entre los autores que se decantan a favor de las tesis que corroboran la drástica reducción de la oferta de empleo - como una consecuencia de lo que Lipietz (Lipietz \& 
Leborgne, 1990) y B. Coriat $(1991,1993,1998)$ conceptúan de "postfordismo" - estaría Gorz (1991, 1994, 2000), quien pronostica la desaparición de los empleos "tradicionales", "estables "y a " tiempo completo". Este autor destaca que, con arreglo a los pronósticos futuristas de la OCDE, dentro de un tiempo la industria no empleará a más del $2 \%$ de la población activa y la agricultura el 1\%. Es más, con el nombre de "re-engineering" ha sido diseñado en EEUU un modelo de "gestión de los efectivos" que combina informatización y robotización, lo que permite obtener el mismo volumen de producción empleando la mitad de capital y una plantilla de asalariados entre un $40 \%$ y $80 \%$ menor. Estas previsiones, aunque en principio pueden parecer un tanto exageradas, sin embargo no dejan de ser indicativas de la existencia de ciertas tendencias, sobre todo en el ámbito "postfordista".

Por otra parte, el Boston Consulting Group ha señalado que la industria alemana dispone de unas reservas de productividad entre un 30\% y un 40\%, y un excedente de trabajadores de aproximadamente 2.5 millones; en el caso de la administración y los servicios la reserva de productividad sería del 50\%. A este respecto, el "re-engineering", así como el "lean production" y el "lean management", que implican un desdoblamiento entre: unidades centrales, dotadas de una eficacia máxima, y unidades que absorben la producción externalizada (subcontratas, pirámides de subcontratación, etc.) con unas condiciones laborales "fuera de normas" o "contingent jobs", indican no únicamente que nos hallamos inmersos en procesos de innovación tecnológica, sino también que dichos procesos, en su concreción, han provocado un empeoramiento de las relaciones laborales. Todo ello permite extraer dos conclusiones:

En primer lugar, la esfera de la producción capitalista emplea un volumen cada vez menor de trabajo para producir un volumen creciente de riqueza. Tal esfera ya no está al alcance de una proporción creciente de la fuerza de trabajo, cualquiera que sea la cualificación de ésta. En segundo lugar, por tanto, sólo pueden crearse empleos suplementarios a través de la redistribución y el reparto de los empleos existentes, por una parte, y a través del desarrollo, por otra, de actividades situadas fuera de la esfera capitalista y que no tengan como condición la valorización de un capital (Gorz, 1994, p. 75).

Asimismo, un premonitorio análisis de "Il Manifesto" (Il Manifesto del 12 de noviembre de 1986), acerca de las modalidades de organización adoptadas por la fracción tecnológicamente más innovadora involucradas en el diseño del "nuevo trabajador", mostraba que la utilización de prototipos informacionales traía consigo un cambio en el modo de producir, esto es:

a) La transformación, cuyo resultado es el producto, se realiza cada vez más en su totalidad por la máquina que efectúa operaciones directamente sobre los materiales;

b) Desde su posición el trabajador se limita a realizar tareas de alimentación, montaje y control por simples o complejas que sean.

Sin embargo, estas modificaciones no sólo han afectado a la división del trabajo o al nexo entre operario y máquina, sino también a la distribución de tareas en el interior del proceso de trabajo. Se ha pasado, en secuencias específicas, de la parcelación extrema y repetitiva del "fordismo" y "taylorismo" a procesos altamente integrados e interactivos en los que la elaboración y el ensamblaje dependen de modelos informáticos que conectan las distintas producciones y, simultáneamente, las producciones con la gestión. De esta manera, principalmente en los segmentos con una elevada intensidad tecnológica, la participación del trabajador se convierte en indirecta o subsidiaria, y las tareas de control y regulación en lo principal. Las competencias y conocimientos o el poder del operario recae en el "sistema de gobierno" y no en la materialidad del trabajo. Este impulso maquínico, superespecializado, sobrepasa con creces el ámbito estricto de las prácticas y estereotipos implicados en la producción de bienes y servicios; trae consigo un cambio cualitativo en la cultura del trabajo que Gorz (1991) describe en estos términos: 
(...) de la masa creciente de saberes desplegados, los individuos no dirigen más que una ínfima parcela. La cultura del trabajo ha estallado en mil pedazos de saber especializado y de este modo ha sido arrancada de la cultura de lo cotidiano. Los saberes profesionales no suministran ni las señales ni los criterios que permitían a los individuos dar sentido al mundo, orientar su curso, orientarse en él. Descentrados respecto de sí mismos por el carácter unidimensional de sus tareas y de sus saberes, violentados en su existencia corporal, tienen que vivir en un medio en vías de dislocación y fragmentación continua, librado a la agresión megatecnológica. Este mundo, imposible de unificar por la experiencia vivida, no es más que el mundo vivido de la dolorosa experiencia. La vida cotidiana ha estallado en playas de tiempos y espacios cortados unos respecto a otros, sucesión de sobresolicitaciones agresivas, de tiempos muertos y de actividades rutinizadas. A esta fragmentación vivida corresponde una (no-) cultura de lo cotidiano, hecha de sensaciones fuertes, de modos efímeros, de diversiones espectaculares y de informaciones fragmentarias (Gorz, p. 117).

Offe (1994, p. 70), por su parte, ya advertía en la primera mita de los 90 acerca del enquistamiento del desempleo en tasas elevadas en la Unión Europea, puntualizando que el éxito de las políticas de ocupación en unos países y regiones comportaba el aumento del desempleo en otras; lo que provocaba, paralelamente, el "desmontaje controlado" de los derechos sociolaborales estatutarios dado el influjo todavía dominante de las teorías adscritas a la "corriente principal": "monetaristas", "expectativas racionales" y "macroeconomía del equilibrio".

Así pues, aunque la producción de riqueza sea mayor, no se incrementa en la misma proporción el empleo, aunque sí se afianza el "jobless growth" y la pobreza. El volumen de lo producido aumenta y además esto ocurre mediante la utilización de procedimientos y tecnologías que requieren una proporción menor de fuerza de trabajo y el recurso de las "externalizaciones". Dicho con otras palabras, globalmente se amplia la desproporción entre la riqueza producida o el valor del excedente y la fuerza de trabajo implicada. Ahora bien, tal estado de cosas suscita, en efecto, como corolario, la cuestión de la distribución o del derecho de los empleados y desempleados a participar de la riqueza producida.

Por fin, uno de los autores que se han pronunciado con mayor rotundidad en favor de las tesis que pronostican la reducción masiva del empleo ha sido Rifkin, tal y como se desprende de este fragmento:

En la actualidad, por primera vez, el trabajo humano está siendo paulatina y sistemáticamente eliminado del proceso de producción. En menos de un siglo, el trabajo masivo en los sectores de consumo quedará probablemente muy reducido en casi todas las naciones industrializadas. Una nueva generación de sofisticadas tecnologías de las comunicaciones y de la información irrumpen en una amplia variedad de puestos de trabajo. Las máquinas inteligentes están sustituyendo, poco a poco, a los seres humanos en todo tipo de tareas, forzando a millones de trabajadores de producción y de administración a formar parte del mundo de los desempleados, o peor aún, a vivir en la miseria (1997, p. 23).

A este respecto, producto de esta Tercera Revolución Industrial”, en EEUU se suprimen 2 millones de puestos de trabajo al año y los que se crean no anulan el efecto del paro estructural. Por otro lado, sostiene que, según el "Wall Street Journal", de hacerse realidad los proyectos de "re-engineering", ello podría acarrear la eliminación a corto plazo de entre 1 y 2.5 millones de empleos anuales. En lo tocante a otro tipo de consecuencias en el plano laboral, Rifkin confirma, tomando como referencia Manpower, multinacional del trabajo temporal, el enorme crecimiento del trabajo temporal. Así, entre 1982 y 1990, el empleo temporal tuvo un crecimiento en EEUU 10 veces mayor que el del empleo en su conjunto. Además, los trabajadores temporales superan el $25 \%$ de la masa laboral. En palabras de Hutchens, citado por Rifkin: "la revolución en los años 90 tiende hacia el empleo 
'just in time' (...)las empresas emplearan a las personas tan sólo si realmente las necesitan"; reconociendo que el impacto definitivo de esta disponibilidad extrema todavía está por llegar (1997, p. 229).

\section{Re-conceptualizar el trabajo}

En este contexto, uno de los aspectos que se ha desarrollado - en relación con los procesos de globalización económica (y política) y monetarización de las relaciones sociales estriba en que las concepciones productivistas, que forman parte de la noción moderna de trabajo que arraiga con el nacimiento en el s. XVIII de la ciencia económica (Naredo, 1996, 1997; Du, 1998), han pasado a ser constitutivas de múltiples acciones, penetradas ahora por criterios de productividad y eficacia economicista, a pesar de no haber estado en el pasado incluidas en la esfera mercantilizada o no haber sido consideradas productoras de valor añadido; tal es el caso de sectores antaño calificados de "improductivos" como ha ocurrido con la enseñanza, la sanidad, el trabajo doméstico o la asistencia a domicilio. Sin embargo, la progresiva integración del circuito de la mercancía en estrecha relación con la mercantilización generalizada de las prácticas sociales y el recurso a tecnologías informáticas ha tornado obsoleta la distinción binaria productivo/improductivo que ha sido reemplazada por una concepción potenciadora de la produtividad general de la socialidad o de las formas de vida. Por otro lado, una de las consecuencias de todo esto es que en áreas y segmentos concretos ha perdido validez la clásica cuantificación del valor de los objetos (mercancías) en función del tiempo de trabajo socialmente necesario que contienen; dinámicas en las que el trabajo reviste una abstracción inusitada debido al papel crucial del trabajo(y del plusvalor) cognitivo, tecnocientífico o en general de tipo inmaterial, en el que intervienen un sinfín de intangibles (esquemas epistémicos y metodológicos, imaginación, creatividad, emotividad, adaptación a la incertidumbre, etc.) y donde la medición objetiva del tiempo de trabajo se realiza en función de una axiomática determinada por la perspectiva postfordista. Dicha situación provoca también la autonomización del salario respecto de lo producido, profundizando más si cabe el carácter de imposición económica (política y cultural) que posee el vínculo entre trabajo y salario. Todo ello es demostrativo, sin duda, de la conveniencia de una puesta al día de la teoría social crítica y, más en concreto, de una teoría de la valorización en el capitalismo industrial/postindustrial.

En cualquier caso, algo que conviene remarcar es que con el cambio tecnológico el saber tecnocientífico o en un sentido genérico el saber inmaterial ligado a la producción (/reproducción) se prefigura como clave de bóveda del capitalismo mundializado. Este saber aparece objetivado en máquinas, reglas y procedimientos. A este respecto, en el "Fragmento sobre las máquinas" de la Segunda Mitad de los "Grundrisse" marxianos, se enuncian ciertas categorías sobre el saber abstracto que incluyen, sobre todo, el saber científico, considerado la principal fuerza productiva, supuestamente autónoma, que desplaza a una posición marginal al trabajo parcializado y repetitivo. Se trata de un saber que cristaliza en el capital fijo, transferido al sistema automático de las máquinas. Marx alude, sobre este particular, a determinados esquemas cognoscitivos abstractos, centro neurálgico de la producción social, que desempeñan la función de principios ordenadores del conjunto de los "ámbitos vitales"; agrupados bajo la denominación de "general intellect". Como apunta Virno:

El desarrollo del capital fijo muestra hasta que punto el saber social general, "knowledge", ha devenido fuerza productiva inmediata y, por tanto, las condiciones del proceso vital mismo quedan bajo el control del "general intellect", remodeladas de acuerdo con ello (Virno et. al, 1990, p. 26). 
El "general intellect" engloba modelos epistémicos articuladores que estructuran la "comunicación social" y el "trabajo complejo de masas" que ahora no es trabajo simple. Quedan incluidos en el concepto de "general intellect" lenguajes artificiales, teoremas de lógica formal, teorías de la información y sistemas de paradigmas epistemológicos, así como juegos lingüísticos e imágenes del mundo. De este modo, los procesos laborales, auténticas "constelaciones conceptuales", pueden funcionar como "máquinas productivas" prescindiendo de dispositivos mecánicos y de válvulas electrónicas (Virno, 2001, 2003).

El concepto de "general intellect" resulta de este modo la avanzadilla de algo que ha sido posteriormente verificado, a saber: la importancia creciente de esa parte del capital que es el "capital cognitivo" - la cual se nutre de la Investigación + Desarrollo + innovación $(\mathrm{I}+\mathrm{D}+\mathrm{i}) \ldots$ - complemento del industrial y financiero. Según Cillario (1996, p. 49-55), este proceso tiene su concreción: por un lado, en lo cognitivo, ingrediente del capital monetario o de la riqueza en general a la que han contribuido las prestaciones reflexivas ; por otro, en el capital/valor cuya existencia productiva/reproductiva discurre interiorizándose en la estructura psíquica y mental de los sujetos donde aparece como "sentido". En efecto, la succión del potencial cognitivo en la cara postfordista del circuito de la mercancía ha reconvertido, contando con el soporte de las TIC, lo que antes eran simples tareas ejecutivas en prerrogativas de ideación, innovadoras para incrementar la productividad. De ahí se deducen dos características que atañen al nuevo formato del trabajo. Una, la "reflexividad", flexión sobre otra flexión en la circularidad producción/reproducción, que incorpora la creatividad como creatividad sometida. Otra, la "disociación psíquica", corte dicotómico a resultas de la internalización por el individuo de los elementos e interacciones del operar productivo/reflexivo; inmersión en el flujo sináptico, sobresaturado, en el hacer/deshacer, formar/disolverse de la "pluralidad de roles" y "expectativas de comportamiento".

Un aspecto esencial, parte de esta transmutación, estriba en lo que Guattari (1987, 1988) califica de "producción de subjetividad". A este respecto, subraya que en el capitalismo postindustrial la centralidad del poder, el foco de atención se desplaza, cada vez más, de las estructuras productoras de mercancías en forma de bienes y servicios hacia las estructuras productoras de sistemas sígnicos y de subjetividad, lo que se lleva a cabo de manera concreta mediante el control que se ejerce sobre los mass media, la publicidad, los sondeos, etc. Como quiera que sea, aquello que es indispensable tener en cuenta es que la "producción de subjetividad", es decir, de conciencia, cultural, dependiente de "sistemas de valores incorpóreos", está en la "raíz", en la base de las nuevas modalidades productivas.

En relación con lo anterior, aparecen determinados rasgos entre los que destaca la pérdida de relevancia del trabajo en su versión clásica (marxiana, ricardiana). Una simple lectura de la información empírica (De la Fuente \& Otazua, 1998, p. 62), permite apreciar que el tiempo dedicado a la producción de mercancía ha disminuido desde las 3000 horas anuales en la Primera Revolución Industrial hasta un promedio de 1700 horas en 1992 que prefigura un amplio abanico que iría desde las 1400 (países escandinavos) a las 1900 horas. Asimismo, si a mediados del s. XIX la dedicación al trabajo suponía un $62 \%$ del tiempo total en la actualidad no va más allá como promedio del 16\%; esto es algo perfectamente compatible con la existencia de variaciones considerables de unos sectores y grupos económicos y de población a otros.

Lo que ponen de relieve estas consideraciones es la necesidad de una categorización distinta a la del concepto moderno de trabajo, "fordista" (y "taylorista"), que designa una serie de operaciones repetitivas, homogéneas, para la transformación de materia tangible en el marco de unas relaciones de poder asimétricas, jerarquizadas verticalmente, rígidas, cuya finalidad predefinida es el aumento del valor del capital. Dicha categorización, heredera de la tradición económico-política y discursiva del trabajo artesanal y del "factory system" decimonónico, y que tiene su prolongación,en el s. XX, con el apogeo "obrerista" y de las luchas obreras y sociales de los 50 y 60, se debilita con los ciclos de lucha de fines de los 60 y 
de los 70 que desembocan, por fin, en la caída de los muros de la fábrica y la subsiguiente emergencia, entre la segunda mitad los 70 y los 80 , de lo que llamamos "metrópoli" o "metrópoli de la comunicación y el control". El nuevo teatro de operaciones que se prepara ya desde los años 70, con la expansión por el territorio de los postulados del mercado que inviste objetos y relaciones, y, más adelante, en los 90, con la financiarización de la economía, requiere, ciertamente, categorías analíticas y prácticas distintas. Con el fin de la vieja fábrica de chimeneas y la implantación de nuevas modalidades tecnológicas el trabajo fordista (y taylorista) se ve sustituido, sobre todo en las áreas y segmentos más industrializados, por la productividad del territorio y de las formas de vida. Simultáneamente, en las zonas y segmentos periféricos, vemos como proliferan modalidades de trabajo que evocan el "capitalismo manchesteriano". El trabajo ya no se circunscribe, por tanto, al espacio cerrado de la fábrica: con la reestucturación ha sobrepasado ese límite y se expande por el territorio para conformar la metrópoli. Así pues, como si de una extraña lógica esquizoide se tratara, paradójicamente, mientras por un lado el desarrollo tecnológico permite disponer de un enorme potencial de reducción del tiempo de trabajo; por otro, se imponen pautas para someter los comportamientos o la socialidad a criterios productivistas y de trabajo convertidos, por tanto, en nuevos dispositivos para la valorización. Negri y Hardt (2003) han definido en términos parecidos la situación a la que nos aboca esta transformación: "en el preciso momento en que la teoría deja de ver el trabajo, el trabajo (en la nueva forma valorizante) se ha tornado en todas partes la sustancia común” (Negri \& Hardt, 2003, p. 18).

\section{Espectro de propuestas}

En este tesitura, cuyo denominador común estriba en reconocer la importancia del cambio tecnológico (técnicas de fabricación y organización) y del régimen sociolaboral en el marco de la global (y local) económico (y político), surgen diversas propuestas. Veamos algunas de sus características básicas. Nos referiremos, en primer lugar, a la muy extendida lectura de cuño neoliberal, "ofertista", "supply side economics" (Cleaver, 1981), que afirma que la creación de empleo depende inevitablemente de la reducción de costes laborales y de la flexibilización normativa y jurídica. En este caso se puede argüir, sin salir de la racionalidad mercantilizante, la existencia de un error conceptual que estriba en ignorar que en realidad, como se ha indicado, son dos los salarios a tener en cuenta; dicho con otras palabras: los salarios no tan sólo representan un "coste de la producción", sino también un "ingreso" que permite el consumo y, por ende, la realización del valor, estimulando retroactivamente la oferta de empleo. Por otra parte, la fe ciega en la capacidad autorreguladora del mercado evocación de la "mano invisible" del "laissez faire" smithiano - ha sido puestas en tela de juicio de un modo patente a raíz, por ejemplo, de las turbulencias desestabilizadoras de los mercados financieros a finales de los años 90 y principios del 2000, profundizando más si cabe la crisis estructural. En efecto, tal fue el caso de la crisis asiática de 1997 cuyo efecto dominó hizo que repercutiera en otras regiones del planeta (Latinoamérica, etc.); o bien, del pinchazo de la burbuja bursátil en el 2000-2001 (mercado de las nuevas tecnologías, etc.) y del derrumbe de la "new economy" (Brenner, 2003; Fernández, 2003).

Desde la órbita socialdemócrata, el "Libro blanco" de Delors - que partía de la aceptación tácita de los "criterios de convergencia" elaborados por la Unión Europea - ha representado una propuesta diferenciada de la de los neoliberales. En él se distinguen varios tipos de desempleo:

a) Desempleo coyuntural producto del desajuste entre incremento de la mano de obra disponible y crecimiento económico; 
b) Desempleo estructural que obedece a varios factores: toma de posición inadecuada en la división internacional del trabajo; falta de flexibilidad en los sistemas de empleo, etc.;

c) Desempleo tecnológico causado por un desfase entre velocidad del cambio tecnológico y adaptación a la nueva situación generada (productos, necesidades, etc.).

A partir de estas premisas se proponen algunas líneas de actuación: promover la educación y el reciclaje permanentes; flexibilizar interna (promover la movilidad funcional y la polivalencia) y externamente (movilidad geográfica) el mercado de trabajo; descentralización empresarial (la autonomía permite reordenar el tiempo de trabajo adecuándolo a la mejora de la competitividad, etc.); modificar las políticas de empleo (paro enraizado, paro de larga duración, etc.); tener en cuenta las necesidades que surgen en el nuevo periodo (adecuar las infraestructuras europeas de comunicación, acondicionamiento con vistas a los nuevos soportes informacionales y a las estructuras en red, etc.). Con todo, en esta situación sin precedentes, en que el desempleo es visto como una de sus secuelas más palpables, el "Libro Blanco" no se muestra partidario como fórmula universal y por ley de la reducción generalizada del tiempo de trabajo o de su reparto, puesto que considera que ello frenaría la competitividad y, en general, la economía. No obstante, reconoce la necesidad de ciertas medidas que en todo caso deberían negociarse empresa por empresa; negociación supeditada a la prospección de "yacimientos de empleo" que previsiblemente aparecerán si somos capaces de "ir al encuentro de las nuevas necesidades" (protección del medio ambiente, servicios asistenciales, ocio, cultura, etc.).

Con un talante no tan moderado han aparecido otras iniciativas promovidas por una izquierda política, cultural, en busca de filones de empleo, preocupada por la posibilidad de un futuro sin trabajo. Una de ellas sostiene que si la oferta de trabajo disminuye, y dado que no se concibe otro medio de disponer de capacidad adquisitiva en el actual sistema económico que recurrir al trabajo, lo mejor es compartir lo que catalogan como supone un bien escaso. En contra de esta interpretación se han aportado, empero, diversos argumentos (Aznar, 1994; Taddei, 1994; Lipietz 1996; De la Fuente \& Otazua, 1998). De la Fuente y Otazua señalan dos. Primero, que al tratarse de trabajo asalariado implica compartir el volumen total de trabajo, pero al repartir la masa salarial entre una cantidad mayor de individuos de hecho se reducen los salarios, habida cuenta, además, de que este reparto afectará ante todo a las bajas cualificaciones; lo que se deduce de esta propuesta es que al repartir el trabajo se reparte el paro. Segundo, ya que preconiza una noción estática que presupone un volumen de trabajo y una masa salarial fijos en una situación cambiante.

Como alternativa, proponen reducir el tiempo de trabajo - instrumento de creación de empleo y reducción del paro - lo que significa tender a trabajar menos sin que conlleve una merma salarial, teniendo en cuenta que aumenta la productividad y, por lo tanto, el volumen de riqueza. Ello comportaría una disminución de la actividad laboral y de la demanda de trabajo, y, paralelamente, un aumento del consumo inducido por los que antes estaban parados. No obstante, surgen algunos interrogantes, como por ejemplo si la propuesta de las 35 horas no se ha quedado corta ante la magnitud del paro existente; o también, si no son incompatibles reducción de la jornada laboral y mantenimiento del salario. Sobre este particular, el "regulacionista" Lipietz (1996) admite que el incremento en el volumen de producción derivado del aumento de productividad no basta para cubrir los efectos derivados de aquella reducción, para lo que sugiere medidas compensatorias (fiscales del tipo impuestos especiales, tope salarial, complementos, etc.). No hay que olvidar, pese a todo, que cuando se han barajado estas cuestiones el empresariado se ha mostrado más proclive a la negociación salarial que a la reducción de la jornada. Otro aspecto a considerar es la posible pérdida de competitividad de las empresas que aplicaran estas medidas. Frente a esto se indica que, aparte de que la reducción del tiempo de trabajo puede traer aparejado incluso un aumento de la inversión productiva, hay que tener en cuenta, en el caso de España, que la mayor parte de los intercambios económicos se efectúan dentro de la Unión Europea, donde la mayoría de 
sus miembros tienen jornadas más reducidas y salarios más elevados. Extremo este confirmado por el Informe del Instituto Nacional de Estadística (INE) de julio de 2005. En el fondo, como afirman De la Fuente y Otazua (1998, pp. 68-74), pervive aquí una lógica posibilista consistente en no sobrepasar ciertos límites macroeconómicos.

Por su parte, André Gorz, sostiene que, dado que en los procesos de producción e intercambio económico se trabaja cada vez menos, tiene que reconocerse el derecho a una remuneración continua, puesto que se produce un volumen creciente de riqueza con un volumen decreciente de trabajo. Por otro lado, la nueva configuración social muestra que el significado y el sentido de los individuos dependen cada vez menos o no dependen del trabajo en tanto que valor ético o como referente identitario. Ha habido una "inversión de valores", una trastocamiento de los "tiempos sociales". Dumazedier, al que se refiere Gorz, sostiene:

(...) la sociedad del ocio no tiene visibilidad social. Se organiza en la niebla (...) Valores colectivos anacrónicos o irreales (...) impiden percibir las nuevas realidades producidas por una especie de revolución de los tiempos sociales (...) Tanto en la izquierda como en la derecha, se mantiene un representación política de la sociedad francesa cada vez más alejada de los problemas reales, vividos por la mayoría a todas las edades de la vida (1995, p. 79).

Todo esto alimenta en ciertos sectores la incapacidad para asumir la diferenciación existente entre un pasado articulado en torno al trabajo y un presente en el que por diversos motivos(económicos, tecnológicos, políticos, axiológicos) el trabajo (no la productividad social) tal y como se concebía (rutinario, simple, circunscrito al puesto de trabajo, identidad política en la cultura obrerista, etc.) ha dejado de jugar el papel vertebrador que se le había atribuido.

En esta situación, en la que el derecho a una remuneración garantizada no puede depender de la posesión de empleo estable, Gorz propone reducir el tiempo de trabajo sin pérdida de remuneración, o bien: “...indemnizar el reparto del trabajo, esto es: otorgar el derecho a una remuneración continua por trabajo discontinuo que incluiría asimilar en tanto que actividad remunerable la realización de tareas de interés social (educativas, culturales, redes de ayuda mutua, etc.). Esta propuesta, que presupone un nuevo contrato social, tiene su plasmación en una remuneración que tendría dos componentes: salario y "segundo cheque", habida cuenta de que el "segundo cheque" se financiaría mediante un impuesto selectivo e indirecto que compensaría la merma de salario derivada de la reducción del tiempo de trabajo.

Desde un punto de vista que comparte la premisa del "jobless growth" (Marazzi, 2003), Offe (1992) arremete contra la idea, propia de los tiempos de la "sociedad del trabajo", en virtud de la cual es la inserción en el mercado de trabajo lo que la permite al individuo obtener la homologación de sujeto normal. En este camino sin retorno, la sociedad del "jobless grrowth" tiene que dotarse de algún mecanismo, perfectamente válido, "derecho ciudadano a una renta básica", que garantice que aquellos que renuncian voluntariamente a que su derecho al trabajo se haga efectivo perciban una "contraprestación" económica financiada por la vía impositiva, la cual, a diferencia de lo apuntado por Gorz, no precisa otro requisito que ser miembro de una determinada sociedad.

Otro enfoque es el de J. Iglesias (1997), que preconiza el derecho de todo ciudadano a una "renta básica". Dicha renta es vista como un "mecanismo redistribuidor" de la riqueza existente, calculada a partir de las posibilidades que ofrece el PSB, y cuya asignación no tiene que depender del lugar que el sujeto ocupe en el sistema productivo (trabajador, parado, estudiante, pensionista, ricos, pobres, etc.). La justificación de esta propuesta - que se apoya en toda una serie de críticas al enfoque neoliberal de la economía, al destacar las nefastas consecuencias que ha tenido para los trabajadores, y en general para la "ciudadanía" - radica 
en que la sociedad y las instituciones deben crear las condiciones que permitan que cualquier individuo pueda gozar del derecho a decidir sin constricciones, lo que incluye la no obligatoriedad de paso por la condición de empleado, acerca de los posible itinerarios de su vida.

Por último, esbozaremos algunas de las ideas de ese espectro multiforme, radical, contrario a la racionalidad predominante del cálculo económico, y que se guía por criterios que son independientes de la ley del valor vigente (Quintana, 2003). En primer lugar, se considera que a resultas de los cambios político-económicos, culturales y tecnológicos que prefiguran el capitalismo financiarizado, una parte de la sociedad, basculando entre la precariedad y el paro, queda prácticamente sin derecho a participar de los beneficios del mercado, puesto que no tienen trabajo remunerado estable ni visos de tenerlo, y sucede que éste es en principio el instrumento necesario para obtener un ingreso que permita adquirir mercancías, sinónimo de satisfacción tangible y simbólica de las "necesidades". Dos, la exigencia del derecho a vivir y no a sobrevivir. En tercer lugar, al presuponer que estamos inmersos en el "todo mercancía", reino del valor de cambio - el valor de uso ha sido engullido por el valor de cambio, por la moneda - se reivindica que los hasta ahora excluidos tengan acceso suficiente al flujo de dinero, el valor de cambio por excelencia y significante dominante. Hay que decir que en esta propuesta, tal y como está formulada, no hay dialéctica ni tampoco contrapartidas, simplemente la exigencia del cumplimiento de un "derecho" que se da por sentado. Metáfora de la reapropiación de la riqueza, del espacio y del tiempo, ejemplificada en el slogan: "dinero gratis". Símil de renta a cambio de nada. Ejemplificación de la crítica de la economía-política y de la cultura que incita, con total obscenidad, a interrumpir, puntualmente, el circuito de la mercancía y del poder. Se trata, por cierto, de una apuesta sin mediaciones. Diferencia no representable que se afirma frente a / contra la diversidad gregaria.

Conviene subrayar, aquí la existencia de algunas afinidades entre la postura del "dinero gratis" y la mantenida por el movimiento de parados en Francia surgido a partir de la asamblea de Jussieu "contra el paro y la precariedad"3. Si bien, hay que decir que éste debe ser catalogado como movimiento contra la precariedad y por la apropiación del valor de uso, mientras que aquél consistiría en algo más específico: visión deconstructiva en pro de la oc(k)upación de porciones del espacio / tiempo de la "metrópoli".

\section{Metamorfosis del trabajo y fragmentos de espacio/tiempo de vida}

Llegados a este punto, diremos que el escenario que se delinea - economía (/política) - mundo, mezcla de orden sistémico y caos - no apunta precisamente hacia la continuidad con algunos retoques de lo que ha sido denominado "sociedad del trabajo", pero tampoco al "fin del trabajo" previsto por Rifkin (1997). Este fragmento de Coriat (1993) acerca de la inviabilidad de la "automatización total resulta a este respecto ilustrativo:

Enunciémoslo desde el principio, el taller - a fortiori la fábrica del mañana - no es una fábrica sin hombres. Esta imagen tenaz, profusamente difundida, no sólo no corresponde a nada observable - si no es en minisecciones de producción - sino que obstaculiza la comprensión de lo que está verdaderamente en juego. El futuro, de ninguna manera, es el de la automatización integral de las tareas y las funciones. Cualesquiera que sean las orientaciones "tecnologistas "localizables aquí o allá en algunas prácticas de empresas, la

3 Editorial Virus ha publicado un texto bajo el título Los parados felices (1998), en el que aparecen diversos escritos relacionados con el tema de la exclusión y con las diversas propuestas para hacer frente a la "dualización", incluyendo los difundidos por la Asamblea de Jussieu. 
“automatización total "es impracticable, tanto por razones científicas y técnicas como financieras, y eso vale para todo el horizonte del futuro previsible (p. 68).

Ahora bien, aunque las cosas de facto sean por el momento como apunta Coriat, no hay que olvidar que a lo largo de la historia el sueño del capital ha sido establecer unas condiciones que le permitieran prescindir del trabajo o cortar el nexo entre el capital y el trabajo para independizarse de la fuerza del trabajo, del trabajo vivo, causa principal y donde ha residido el núcleo básico de la crisis. Y esta meta, hecha realidad solamente en parte con la Tercera Revolución Industrial - la Primera estuvo representada por la "gran fábrica" y la Segunda por el "fordismo" y el "taylorismo" - podemos rastrearla en la propia genealogía moderna del trabajo y de la conflictiva relación entre el trabajo y los cambios técnicos (económico y políticos) en las distintas etapas. Sobre este particular resulta esclarecedor que ya en los albores de la Primera Revolución Industrial, Andrew Ure, temprano apóstol de la automatización, viera en la máquina hiladora autoactivada, "Hombre de Acero", el instrumento idóneo para acabar con los "abusos" de los hiladores y de este modo devolver el orden al agitado cosmos fabril, puesto que como es sabido las máquinas no hacen huelgas ni sabotajes.

Así pues, si dirigimos nuestra atención a lo acontecido en las últimas décadas podremos comprobar las consecuencias ambivalentes o polivalentes de los nuevos sistemas tecnológicos y de su utilización. En efecto, por un lado, percibimos cómo dichos sistemas (técnicas de fabricación y modalidades organizativas), cuya principal apoyatura reside en el lenguaje y en la microelectrónica, permiten un crecimiento exponencial de la productividad y de la riqueza y poseen un enorme potencial de reducción del tiempo de trabajo y, por consiguiente, de disponibilidad de tiempo de no trabajo, libre o no; no es posible omitir que el tiempo institucional de no trabajo es tiempo de prerrequisitos de producción/reproducción mercantilizante. En cambio, por otro, la forma concreta que ha adoptado su aplicación en un marco vertebrado por la axiomática del mercado ha comportado la persistencia junto al trabajo cognitivo de modalidades que remiten al "flujo continuo" del "fordismo", al fraccionamiento milimétrico de Taylor y al "scientific management", e inclusive a formatos muy anteriores. Lo que se detecta es, a fin de cuentas, que dichas aplicaciones denotan una diversidad de situaciones tecnológicas y de condiciones sociolaborales - verdadera "dualización social" (estables y precarios o excluidos) - que en líneas generales se distribuyen según las dos matrices básicas que hemos definido como: "neofordista" y "postfordista".

En definitiva, lo que se percibe es un panorama incierto, lejos de las fantasías de algunos tecnólogos y de cierta literatura de ficción cuya concreción esta ahí: un importante salto técnico y organizativo (y socioeconómico) de consecuencias paradójicas, pero cuya materialización efectiva ha significado la exclusión o la invisibilización de una parte de la sociedad que ha dejado de ser útil para el ciclo de la mercancía o que ha dejado de tener valor de cambio. Ante esto han surgido distintas propuestas alternativas entre las que habría que destacar aquellas que enfatizan determinadas reivindicaciones legítimas y que manifiestan su oposición a cualquier política dualizadora. En cualquier caso, para finalizar nos parece pertinente, además de compartir con Mumford (1967) el rechazo de las "abstracciones" vinculadas al progreso tecnológico y a la acumulación de capital/, dejar constancia de que problematizar - en el sentido foucaultiano del término - esta temática permite sacar a relucir o enlazar con cuestiones planteadas por los "ludditas" en favor de "otro tipo de progreso", o bien, desde otro ángulo, con la crítica a la cultura "trabajista" y "economicista", sinónimo de recuperación de fragmentos de espacio/tiempo de vida, que destilan algunos espléndidos textos de la antropología política de Pierre Clastres. 


\section{Referencias}

Aronowitz, S. \& Di Fazio, W. (1994). The jobless future. Minneapolis: University of Minnesota.

Aznar, G. (1994). Trabajar menos para trabajar todos. Madrid: HOAC.

Bermejo, R., Naredo, J. M. \& Offe, C. (1997). ¿Qué crisis? Donostia: Gakoa.

Brenner, R. (2003). La expansión económica y la burbuja bursátil. Madrid. Akal.

Castells, M. (1998). La era de la información. La sociedad en red (Vol. 1). Madrid: Alianza Editorial.

Cillario, L. (1996). L'economia degli spettri. Roma: Manifestoibri.

Cleaver, H. (1981) Supply-side economics: the new phase of capitalist strategy in crisis. Babylone, 0, $25-45$.

Coriat, B. (1991). Penser à l'envers. Paris: Cristina Bourgois.

Coriat, B. (1993). El taller y el robot. México: Siglo XXI.

Coriat, B. (1998). Made in Japan. Paris: LGF.

De la Fuente, M. \& Otazua, G. (1998). Reducción del tiempo de trabajo y paro masivo: viejas respuestas a nuevos problemas. Arxius, 2, 69-92.

Du, L. \& King, A. (1991). The first global revolution: a report by the Council of the Club of Roma. New York: Pantheon.

Deleuze, G. \& Guattari, F. (1988). Mil Mesetas. Valencia: Pre-Textos.

Fernández, R. (2003). Capitalismo financiero globlal y guerra permanente. Barcelona: Virus.

Gorz, A. (1991). Métamorphose du travail. Paris: Galilée.

Gorz, A. (1994). Salir de la sociedad salarial. Debats, 50, 74-83.

Gorz, A. (1997). Misères du présent. Richesse du possible. Paris: Galilée.

Harvey, D. (1998). La condición de la posmodernidad. Buenos Aires: Amorrortu.

Iglesias, J. (1997). El derecho ciudadano a una renta básica. Madrid: La Catarata.

Leborgne, D. \& Lipietz, A. (1990). Idées fausses et questions ouvertes de l'après-fordisme. Coloquio: Patthways to Industialization and Regional Development. Lake Arrohead. UCLA.

Lipietz, A. (1996). La société en sablier. Paris: La Découvert.

Marazzi, C. (2003). El sitio de los calcetines. El giro lingüístico de la economía y de sus efectos sobre la política. Madrid: Akal.

Meda, D. (1998). El trabajo. Barcelona: Gedisa.

Mumford, L. (1967). Technics and Human Development (Vol. 1). New York: Harvest-HBJ Book.

Naredo, J. M. (1996). La economía en evolución. Madrid: Siglo XXI.

Negri, A. \& Hardt, M. (2003). El trabajo de Dionisos. Madrid: Akal.

Offe, C. (1992). La sociedad del trabajo. Madrid: Alianza Universidad.

Offe, C. (1994). iPleno empleo? Debats, 50, 68-73.

Quintana, F. \& Pin, R. (1980). La sociedad: nuevo marco de producción. Barcelona: Hacer.

Quintana, F. (Org.). (2002). Asalto a la fábrica. Luchas autónomas y reestructuración capitalista 19601990. Barcelona: Alikornio.

Quintana, F. (2003). Trabajo, neuromagma y fisuras. Athenea Digital, 3.

Rifkin, J. (1997). El fin del trabajo. Barcelona: Paidós.

Rodriguez, A. (1998). Trabajar, repartir, compartir. Arxius, 2, 90-92. 
Soja, E. W. (2003). Postmetropolis. Oxford: Blackwell.

Taddei, D. (1994). Los efectos sobre el empleo de la reorganización-reducción del tiempo de trabajo. Revista de Economía y Sociología del Trabajo, 15/16, 118-132.

Virno, P., Agamben, G., Berti, L., De Caroli, M. \& Piperno, F. (1990). Sentimenti dell'aldiqua. RomaNapoli: Edizioni Theoria.

Virno, P. (2001). Grammatica della moltitudine. Catanzaro: Rubbettino.

Virno, P. (2003). Virtuosismo y revolución. Madrid: Traficantes Sueños.

Endereço para correspondência: fqcastello@yahoo.es

Recebido em: 05/04/2004

Pareceres enviados em: 04/08/2004

Aprovado em: 15/04/2005 